\title{
Scientific organization of innovative labour
}

\author{
Andrey Kuznetsov ${ }^{1 *}$, Nikolai Zakharov $^{2}$, and Marina Perfiljeva ${ }^{2}$ \\ ${ }^{1}$ Udmurt Branch of the Institute of Economics, Ural Branch of the Russian Academy of \\ Sciences. Izhevsk. Russia \\ ${ }^{2}$ Herzen State Pedagogical University of Russia. Saint Petersburg. Russia
}

\begin{abstract}
The industrial revolutions that have passed so far have been an alternation of "machine revolutions" and "labor organization revolutions". The third industrial revolution, which created the modern digital communication world, became a prerequisite for the formation of a new organization of work. This new organization is, first of all, the organization of labor of workers involved in the development of a new product, or the organization of innovative labor of workers. The study of the types of innovative labor shows that at least three models need serious improvement, which the authors have assigned the following names: "design" model, "competitive" and "creative". The scientific organization of innovative labor involves identifying for each model: necessary and sufficient working conditions, including everyday and professional comfort; determination of conditions for the formation of motivational guidelines adequate to their activities among members of collectives engaged in innovative work; developing a clear incentive program based on legal and simple principles of rewarding and punishment.
\end{abstract}

\section{Introduction}

Klaus Martin Schwab, founder and executive Chairman of the Davos Forum, in his book "The Fourth Industrial Revolution" [1] revealed the impressive prospects of the coming Fourth Industrial Revolution. The perspectives presented by the outstanding modern German scientist have stimulated worldwide active scientific research interest in the problems of global technogenic changes and in the peculiarities of human activity, human labor in the coming new era.

Many of his views on the near future, on global technogenic transformations, for us, living at the turn of the XX/XXI centuries, do not cause any doubt, because before our eyes, within two to three decades, within one generation lifespan, there were amazing cardinal changes (from the queue to the library - to the Google search engine, from the dial-tone telephone to the smartphone, from the processing of data arrays using a calculator to Excel tables and SPSS - and this is not a complete list of the most amazing changes). And we are quite ready to expect such changes in the future.

Moreover, in order to clearly present the long-term prospects shown by the German economist Klaus Schwab, it is necessary to stand firmly on the scientific foundation providing the vision of these prospects. This means that it is necessary to have a clear picture of "road signs", and maybe obstacles awaiting us in the future. The best way to understand what to expect ahead is to assess the patterns of the path travelled. In this regard, let us consider the main patterns of the previous industrial revolutions.

\section{Problem statement and methodology}

According to the authors, the following industrial revolutions should be considered:

Zero Industrial Revolution - the emergence of the manufactory. The manufactory played an important role: based on labor division, manual labor was organized, using the simplest hand tools. And due to the labor organization of workers armed with such tools, productivity has significantly increased.

The manufactory, which provided a new organization of labor and increased productivity, formed the production need for a constant increase in energy supply. The first machines appeared precisely in manufacturing first, powered by humans and animals, then by wind and water.

The First Industrial Revolution is the emergence of powerful machines using steam, oil, coal, and then nuclear decay energy.

The machines using the powerful energy contained in fossil resources have provided a sharp rise in productivity.

In this regard, it should be noted that despite the appearance of new tools - machines with high energy capacity, the organization of labor remained the same manufacturing. Such kind of labor organization was not suitable for production, equipped with machines using energy incomparable with manufacturing production. Consequently, there was a need for a new labor organization required for machine production. Thus, there was a need for a new industrial revolution.

* Corresponding author: alkuznetsov63@mail.ru 
The Second Industrial Revolution is mainly and essentially the emergence of a scientific labor organization and the immediate introduction of scientific developments into production. The foremost examples of the Second Industrial Revolution are the moving assembly line introduced by Henry Ford in the United States in 1908 and the steel rolling mill by Karol Adamiecki in Russia in 1901. Behind the vivid examples is a real revolution, a mass transition to scientific forms of labor organization in all industrial countries, no matter what they are called - capitalist or socialist, democratic or totalitarian. The labor organization based on scientific achievements is the essence of the Second Industrial Revolution.

The twentieth century is a century of scientific and technological development. The very name reflects the direct connection of technology and science, the constant improvement of technical systems based on scientific research. This was the basis for the fundamentally new "machines" creation, and their further widespread production - electronic computers. And along with the electronic computers, the development of technical communication tools begins.

The Third Industrial Revolution is taking place at the end of the twentieth century. It was vividly described by the American economist Jeremy Rifkin in his book "The Third Industrial Revolution" [2]. The result of this revolution is the transition to natural energy sources. And digital technologies become the essence.

The Fourth Industrial Revolution, according to Klaus Schwab and his critics, is associated with the processes of man displacing from the production sphere and replacing him with complex machines.

This is the most general outline of the sequence of industrial revolutions.

Proceeding from this description, there is every reason to conclude that there is a pattern in the dynamics of industrial revolutions - "machine" revolutions alternate with "organizational" ones:

The "manufacturing" labor organization (or the Zero Industrial Revolution) causes the appearance of production machines (which is actually the First Industrial Revolution), and these, in turn, stimulate the emergence of the "scientific labor organization" (the main characteristic of the Second Industrial Revolution), which leads to the appearance of "digital and communication machines" (that is, to the Third Industrial Revolution).

There is every reason to believe that after the Third Industrial Revolution there should be another "organizational" revolution, by analogy with the "manufacturing" and "scientific" ones. And it is this industrial revolution that will be the condition for the revolution that Klaus Schwab called the Fourth.

Consequently, we will call this "organizational" revolution - revolution 3.5, i.e. "3.5 Industrial Revolution", "3.5 Industry" and consider its influence at present.

\section{Problem solution}

It is an important fact that at the beginning of the twentieth century, the share of "time for product development" was about $20 \%$ and $80 \%$ was the technical production process. And at the beginning of the XXI century, everything is the opposite $-80 \%$ [3] is the share of time spent on product development today, while $20 \%$ of the time is spent on production. This indicates that the production process is quite perfect. But the process of product development needs improvement and the creation of a new labor organization.

Previous "organizational revolutions" have improved physical labor. And today, this work is increasingly being transferred to robots and manipulators. But there is another human labor that needs to be organized - the development of a new product, which is called "innovative" nowadays. Its fundamental point is that either one person or a group of people develop a new product without any specific technical task, but aiming at finding "something" new that will attract consumers (or in some other way provide the customer with a competitive advantage).

To date, the arsenal of experience in organizing the work of developers or project teams is not rich. A lot is reported about the working conditions of Google and Mail employees [4]. There are work descriptions of scientific research teams [5]. There is an increasing number of publications about the labor organization of research and development teams aimed at nuclear bomb creating, both in our country and in the United States [6] - very interesting information about the scientific teams work organization.

This interesting and diverse information requires special analysis, therefore, it is necessary to continue the study of various types of developers labour.

Let us consider the variants for organizing the work of developers:

Variant 1. "Rationalization", or improvement of the production process.

Variant 2. A "project" is essentially a search for a solution to the stalemate that an enterprise or institution is experiencing or approaching to. The task of the project team is to find a new promising path.

Variant 3. "Race". A striking example is the implementation of nuclear programs in the United States and the USSR, as well as space projects in the 60s between the countries.

Variant 4. "Surprise" - creating a product that will surprise and interest many people. The activity of the "Apple" company serves as a notable example of this variant, although there are many examples in other areas - for example, artistic creativity: the release of a new film, book, musical composition, painting.

Let us consider these variants as models for organizing the work of developers (or using the modern terminology - the organization of "innovative" activities).

Variant 1, or the first model, which we will call "rationalization". The only model for organizing the 
work of developers (or innovative work), which is fully developed and fully applicable. This could be exemplified by the activity of Henry Ford to improve the car production line, and which he described in his book "My Life" [7]. The system of rationalization activity applied in the Soviet Union since the 30s [8]. And, of course, Japanese quality control circles [9].

In its broadest sense, the process of rationalization activity is as follows:

- First, it is a creation of an organizational system motivating employees to make proposals to rationalize and improve the existing production system.

$\circ$ this motivation system can be clearly ideological in nature, as in the USSR,

o or be permeated by the corporate unity spirit, as in Japan,

- or business spirit, as in the United States,

- but in all cases, it provides the employee with a motivational mood, which can be expressed by the formula: "I am interested in solving this problem". It is necessary to pay attention to the fact that the rationalization activity "will not work" if such a motivating system is not developed beforehand, which will create a socio-cultural environment that sets the rationalization mood [10];

- secondly, under the influence of a motivating mood, the employee constantly searches for and discovers the problem;

- thirdly, based on his professional competence, he finds a solution to overcome the problem;

- fourthly, the employee applies to the competent authority, which evaluates it and, in case of positive assessment, usually ensures the implementation of this application;

- fifthly, the employee receives a reward for his "innovative suggestion";

- sixthly, the employee-innovator by his example encourages other employees to innovate.

This is the basic scheme - and therefore it is the same for the USSR, the USA, and Japan, although each country had its own specific cultural differences. To date, this model is developed and can be quite successfully applied. Its main focus is to improve the existing production process.

Variant 2, or the second model, we will call it "project". This model becomes relevant when a company needs to diversify or find new ways of development. This happens when the company finds itself at an impasse or is approaching it. A separate case is when a newly created company is looking for its own path.

Usually, several project groups are formed to find new directions in the hope that at least one group will open up an interesting perspective.

Project team activity process:

- working conditions are characterized by:

- time of execution. The activities of the project team are time-limited. The validity period of such a group is determined by the relevance of the product being created. If the need for the product becomes irrelevant, the group is dissolved.

- production needs, and therefore proceed from the capabilities of the enterprise. So the working conditions can be neither "luxurious" nor "ascetic", but they should:

- first, motivate the group to achieve the result, and exclude other motivating factors:

Example (case): a specialist was invited to the project group, for whom the living conditions and provision within the project group were significantly higher than usual ones, so his main focus became not a professional activity, but the preservation of these living conditions. The opposite example, a specialist experiencing household discomfort will not be able to focus on work.

- secondly, professional tools should be adequate for the task to resolve the problem.

A hypothetical example, a surgeon can operate with a knife, but the result will be better if he uses a set of surgical instruments produced by a reputable company.

- thirdly, representatives of the project group should have unrestricted access to their workplace (without regime restrictions). In this case, the company should adapt to the mode of the project group (and not vice versa).

- motivational system:

○ the company should have a clear motivating factor that encourages employees to join the project group and actively participate in the creation of an innovative product. The motivating factor is the reward expected by the employee, and the one that everyone needs individually (for someone it may be participation in the profit from the project, for others the Star of Hero of Labour - everyone expects his own reward);

$\circ$ on the other hand, future members should be aware of the losses extent, if their group fails.

- the problem that needs to be solved should be clearly stated to the project group;

- the group is formed on the basis of solving the problem

Organizing the work of the project group is very expensive, and the result would be reached in the unlikely case (because not all groups can solve the problem they face). This is the main stopping factor in the creation of project groups when the company management faces problems of further development.

The third Variant, or the competitive model - in a certain sense, is a variation of the second model, it is almost the same project group, but put in a competitive environment. Nuclear projects, the space race between the United States and the USSR are the actions of project groups in competition with each other. The components of the labor organization are similar to the compounds of the second model, but a very important component is added - the "espionage" of the competitor achievements. The results of this "espionage" can serve as research 
material for the activities of the project group, influence the improvement of labor organization, and act as an intellectual and labor incentive. That is, the obtained "intelligence" material can open up new solutions for researchers (intellectual incentive), and information about the achievements of a competitor can encourage higher labor activity (labor incentive).

This model is even more expensive than the second one. And it also does not guarantee success.

Variant 4, or "creative model". This model can be represented by variations of both the activities of a group and an individual employee. This model includes all the components of labor organization inherent to each model described above.

Its main difference from other models is that it cannot be created for a certain period of time, it is effective only if it acts constantly.

The motivational core of this model is in principle similar to other models, and the main factor is the internal mood of the participants to solve the addressed problem.

Working conditions of the creative worker or group are essential within this model. To date, there are different opinions regarding the working conditions for such activities. Examples of labor organization for creative workers are diverse. Many examples demonstrate that the working conditions of creative workers are such that they do not experience even the slightest discomfort in anything. There are opposite examples demonstrating that ascetic, even "Spartan" working conditions are typical conditions for creative activity.

These are some examples lacking a scientific basis for the phenomenon that certain conditions can affect the effectiveness of creative work.

Therefore there is a need for assessing the impact of working conditions on creative work. This is the first research goal sought by the authors of this article.

Among the parameters of working conditions, there is, in our opinion, the most important - "tools for creative work".

The term "tools for creative work" is enclosed in quotation marks since relevant clarifications are required. The creative workers in their activities use a variety of tools, sophisticated equipment and devices which are called the working tools by the authors of the article.

We differentiate the tools into two types: tools necessary for activities according to a given "algorithm" and for activities without any established algorithm, we will call them working tools for "search". With their help, the creative workers perform search activities and do not perform work according to a given algorithm (although search activities do not exclude individual procedures performed according to the algorithm).

To study the work of a creative worker, it is necessary to investigate the influence of the "tools of a creative worker" factor on the effectiveness of his activity. For this purpose, we will single out the parameters of the study on our phenomenon: "tools for creative work".
So, the parameters of the study on the" tools for creative work" phenomenon include the following components:

1. "adequacy" of the tools to this creative activity:

1.1. creative worker proficiency in tools necessary to solve the problem under study;

1.2. these tools are among the best for solving similar tasks;

2. accessibility of tools - to what extent the tools are available to the creative worker, or what are the limitations in accessibility:

2.1. due to the specifics of the enterprise mode;

2.2. due to the peculiarities of the financial responsibility of the creative worker;

2.3. due to the inability of the company to acquire the necessary "tools" - the lack of the necessary funds;

2.4. due to the uniqueness of the tools and the existing queue for their receipt, or any other distribution system;

3. professional development of a creative worker focused on mastering modern "tools".

Along with the working conditions, an equally important phenomenon is the motivation of creative workers. There are opposite views in public opinion. On the one hand, the creative worker is motivated by the work itself and ignores other incentives. On the other hand, a creative worker will be efficient only when all his needs and even "whims" are instantly satisfied.

This is existing in public opinion idea on the motives and incentives for creative work. The main conclusion here is the following -the motives for creative work have not been studied yet. Therefore, the third research task of the authors is to investigate the motives for creative work, and on the basis of this - to identify effective managerial incentives for creative work.

This is the set of tasks for the study of innovative labor by modern socio-economic sciences.

\section{Conclusion}

Proceeding from the patterns of industrial revolutions, the authors believe that the next Fourth Industrial Revolution, justified by K. Schwab, should be preceded by an "organizational" industrial revolution, which can be conditionally called "3.5 Industrial Revolution", "3.5 Industry". This revolution should be based on the scientific organization of innovative work.

The study of the types of innovative labor shows that today only one type of innovative labor - rationalization activity -fully corresponds to the Scientific Organization of Labor. Or activities for the improvement, rationalization of technological processes.

The system of rationalization activity was formed in all industrial countries, acquiring its own cultural specifics. That is why "Japanese quality control circles", "Ford innovations", "Soviet innovators" seem so different. But all of them solved the same problem, and despite the external differences, they had similar organizational structures of the labor incentive system. This innovative work, aimed at the scientific 
improvement of technologies, based on scientific achievements, has been constantly self-improved. That is why this model, without experiencing Future Shock, entered the XXI century and feels completely free, as in the twentieth century.

The other two models - project and competitive need to be improved, under the modern realities.

But their improvement depends on the improvement of the oldest type of innovative work - creative. And its study involves a number of research goals related to the assessment of the impact on creative work:

First, the study of working conditions;

Secondly, the study of the "tools of the creative worker";

Thirdly, the study of current incentives and motivations.

\section{References}

1. K. Schwab, The Fourth Industrial Revolution. (New York: Crown Publishing Group, 2017).

2. J. Rifkin, The Third Industrial Revolution. Palgrave MacMillan, 2011

3. A. Chechulin, O. Roy, S. Shelonaev, E. Knyazeva, Conference Proceedings: The impact of Industry 4.0 on job creation 2020.(Trenčín: FSEV TnUAD), pp. 106-112

4. A. Chechulin, A. Kuznetsov, V. Grakhov, M. Perfiljeva, Science and technology. 19(2) 125-129 (2020)

5. R. Rodes, The Making of the Atomic Bomb. (NY. Paperback, 1986)

6. H. Ford, My Life And Work. (Paperback, 2008)

7. All-Russian Society of Inventors and Rationalizers Retrieved from: http://www.ros-voir.ru/

8. W. Deming, The Essential Deming: leadership principles from the father of quality. (NY, McGrowHill, 2013)

9. N. Zakharov, The organizational behavior of civil servants. (Moscow, 2021) 